\title{
SARS-Cov-2 Neurological Infection: Implications and Possible Mechanisms
}

\section{Marco Antônio Machado Schlindwein, Letícia Caroline Breis*, Isabelle Pastor Bandeira and Marcus Vinicius Magno Gonçalves, MD, PhD}

Department of Medicine, University of the Region of Joinville, Santa Catarina, Brazil

*Corresponding author: Letícia Caroline Breis, Student, Department of Medicine, University of the Region of Joinville, Rua Ministro Calógeras, 439, Bucarein, Joinville, Santa Catarina, Brazil, 89202-207, Tel: $+5547991760101$

\begin{abstract}
COVID-19 is an emergent disease with reported neurotropism and neuroinvasion, although its pathophysiology is not yet understood. We present the newly discoveries and hypothesis for SARS-Cov-2 neurological infection.
\end{abstract}

\section{Keywords}

SARS-Cov-2, COVID-19, Anosmia, Hypogeusia, ACE2

Neurotropism is a well established characteristic in coronaviruses infections in humans and animals [1$3]$. With the emergence of the new coronavirus SARSCoV-2, its neurotrophic activities begin to attract attention, with a study proposing an effect in the respiratory distress caused by neuroinvasion [4].

A study proposed two possible neurotrophic paths for the SARS-CoV-2 -- gaining access to the central neural system (CNS) via general circulation disrupting the blood brain barrier [5] or via the olfactory bulb that intimately related with the cribriform plate and so giving the virus access to the CNS [5]. The last one is a common route for respiratory virus to enter the CNS [2] and is possibly related to hyposmia in an early state of the disease (Figure 1) [5].

These assumption correlates with clinical findings in a study conducted by Mao, et al. that presents 218 confirmed patients with SARS-CoV-2 infection - 53 (24.8\%) of those who had CNS involvement were related to more severe disease and laboratory differences, espe- cially lower lymphocytes count, compared to patients without CNS involvement [6]. A similar correlation showing lower lymphocytes count was found in children with neurological human CoV infection compared to respiratory human CoV patients [7].

Patients with peripheral nervous system (PNS) symptoms had hyposmia and hypogeusia and presented no laboratory differences compared to patients without PNS involvement [6], indicating that these symptoms can be prodrome of a more serious neurological involvement - although more data is needed - or the low lymphocytes and immune dysfunction are needed for a CNS infection.

Recently, the first case of encephalopathy associated with SARS-COV2 infection described was published. The patient rapidly progressed from fever and cough to an altered mental status, headache and unresponsive to verbal commands, with no alterations in the liquor, suggesting that the blood brain barrier was not affected in the patient [8].

In conclusion, SARS-Cov-2 infection is an emergent disease whose pathophysiology is not yet understood, but neurological involvement is already established. Hyposmia and hypogeusia have been related in patients with COVID-19 and must be considered as symptoms of SARS-Cov-2 infection, even if patients with those symptoms were previously considered asymptomatics.

Citation: Schlindwein MAM, Breis LC, Bandeira IP, Gonçalves MVM (2020) SARS-Cov-2 Neurological Infection: Implications and Possible Mechanisms. Int J Brain Disord Treat 6:035. doi.org/10.23937/24695866/1410035 


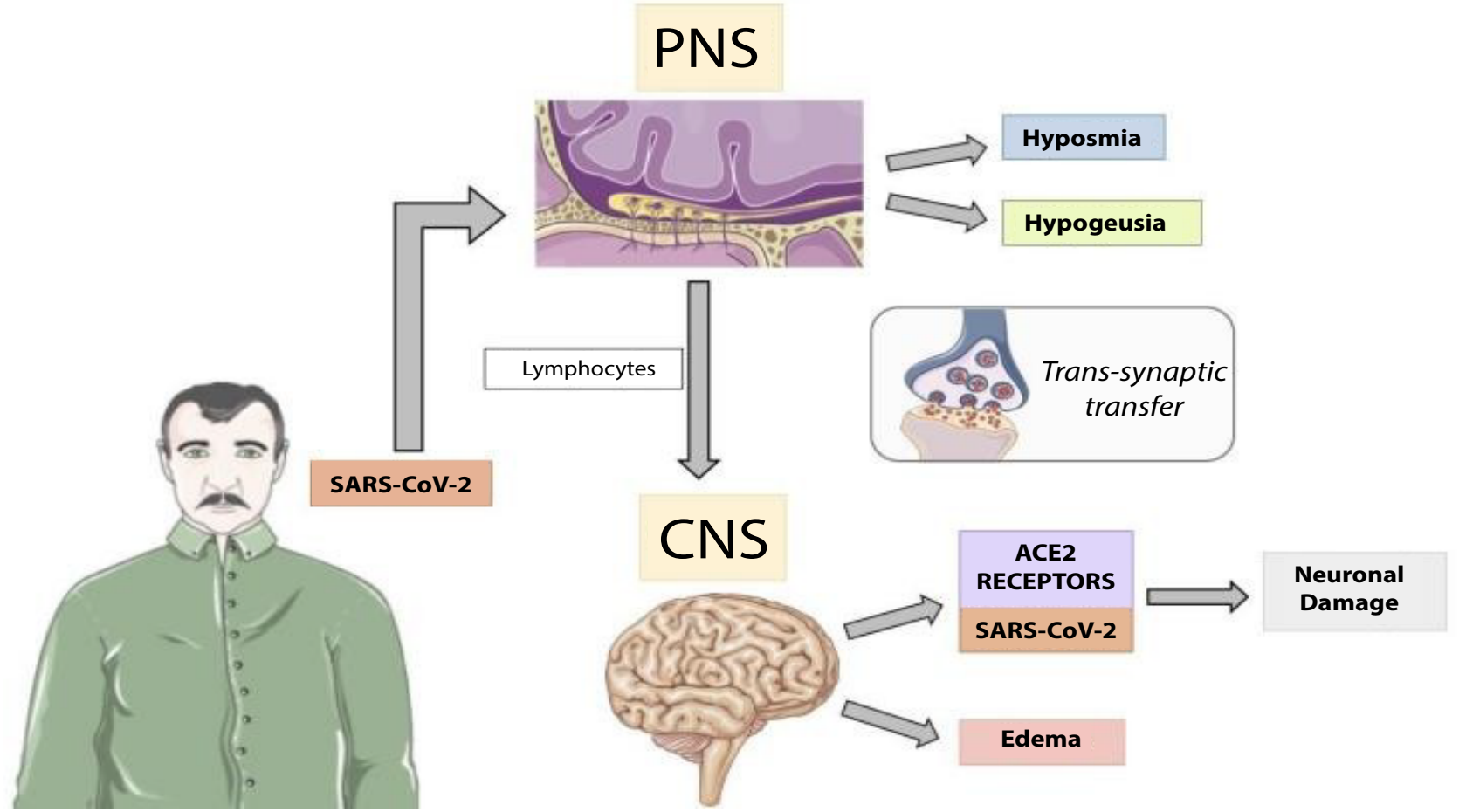

Figure 1: The image represents the SARS-CoV-2 gaining access to the olfactory bulb and then, via transsynaptic transfer, accessing the Central Nervous System (CNS), especially in patients with lower lymphocytes count $[4,6]$. It progresses with CNS symptoms, infecting neurons by binding in Angiotensin conversion enzyme 2 receptor (ACE2) [5]. Images acquired at: http://smart.servier.com/.

\section{Financial Support}

No financial support.

\section{Material Support}

No material support.

\section{Conflict of Interest}

All authors declare that there are no conflicts of interest.

\section{References}

1. Desforges M, Le Coupanec A, Dubeau P, Bourgouin A, Lajoie L, et al. (2019) Human Coronaviruses and other respiratory viruses: Underestimated opportunistic pathogens of the central nervous system?. Viruses 12: 14.

2. Bohmwald K, Gálvez NMS, Ríos M, Kalergis AM (2018) Neurologic alterations due to respiratory virus infections. Front Cell Neurosci 12: 386.

3. Bergmann CC, Lane TE, Stohlman SA (2006) Coronavirus infection of the central nervous system: host-virus standoff. Nat Rev Microbiol 4: 121-132.

4. Li YC, Bai WZ, Hashikawa T (2020) The neuroinvasive potential of SARS-CoV2 may play a role in the respiratory failure of COVID-19 patients. J Med Virol.

5. Baig AM, Khaleeq A, Ali U, Syeda H (2020) Evidence of the COVID-19 Virus targeting the CNS: Tissue distribution, Host-Virus interaction, and proposed neurotropic mechanisms. ACS Chem Neurosci 11: 995-998.

6. Mao L, Wang M, Chen S, He Q, Chang J, et al. (2020) Neurological manifestations of hospitalized patients with COVID-19 in Wuhan, China: A retrospective case series study. medRxiv.

7. Li Y, Li H, Fan R, Wen B, Zhang J, et al. (2016) Coronavirus infections in the central nervous system and respiratory tract show distinct features in hospitalized children. Intervirology 59: 163-169.

8. Filatov A, Sharma P, Hindi F, Espinosa PS (2020) Neurological Complications of Coronavirus Disease (COVID-19): Encephalopathy. Cureus 12: e7352. 